\title{
Upcycling Space Structures
}

\section{Waste as a new structural material}

The construction industry's contribution to the deterioration of Earth's ecosystem is huge. 11\% of all anthropic greenhouse gas emissions worldwide are due to the construction, demolition, and transformation of buildings and infrastructure. ${ }^{1}$ Construction and demolition waste are the largest waste stream by volume and weight in the European Union making up about a third of all waste produced ${ }^{2}-$ other continents follow the same trend or are doomed to follow it in the near future. The construction industry contributes to both natural resource depletion and the degradation of ecosystem services. ${ }^{3}$ By $2050,70 \%$ of the world's population will live in urban areas ${ }^{4}$ : growth and densification of cities will accelerate the obsolescence of buildings, leading to their premature partial or full demolition.

The structural designers' toolset to tackle this multifaceted environmental challenge traditionally consists in (1) avoiding waste and new production by re-assessing and/or improving existing structures; (2) reducing newlyproduced material volumes by optimizing structural layouts and sizing; and (3) substituting classical materials with low-carbon alternatives - e.g. bio-based or recycled materials. While these three strategies are necessary, they are not satisfactory.

The current special issue explores the potential of a fourth strategy, consisting in designing new structures, and in particular space structures, made of reused components. Contrary to recycling, the aim of component reuse is to avoid reprocessing material and to make the most of the geometrical features and mechanical capabilities of given products, while extending their lifespan. In other words, component reuse aims at designing structures that upcycle waste generated elsewhere. From sorting out the inherent variability of a reusable set of components, to dealing with the incomplete description of their predefined capabilities, the change of paradigm triggers a series of new design tasks that are yet to be supported by appropriate algorithms and computational tools. More importantly, a whole new world of design opportunities opens up.
International Journal of Space Structures 202I, Vol. 36(4) 25I-252 (C) The Author(s) 2021 Article reuse guidelines: sagepub.com/journals-permissions DOI: 10.1 I 77/095605992 I I068076 journals.sagepub.com/home/sps

(9SAGE
The papers in this special issue address these challenges and opportunities frontally. The first one explores the reuse of steel or timber bar members in spatial truss layouts. It is authored by J. Brütting from EPFL, and P.O. Ohlbrock, P. D'Acunto, and J. Hofer from ETHZ. The second one studies the reuse of non-standardized metal sheets for corrugated shell structures. It is authored by S.M. Moussavi, H. Svatoš-Ražnjević, A. Körner, Y. Tahouni, A. Menges, and J. Knippers from the University of Stuttgart. The third one deals with the reuse of small timber pieces for reciprocal floor systems. It is authored by D. Parigi and L. Damkilde from Aalborg University. The fourth one addresses the reuse of thin strips with rectangular sections - e.g. skis - in elastic geodesic gridshells. It is authored by C. Haskell, N. Montagne, C. Douthe, O. Baverel from ParisTech, and C. Fivet from EPFL. The fifth one considers the reuse of magazines to form structural membranes. It is authored by A. Le Pavec, S. Zerhouni, N. Leduc, K. Kuzmenko, and M. Brocato from the ENSA Paris-Malaquais.

The idea of this special issue emerged during discussions within the Working-Group 18 on "Life-Cycle Design and Assessment of Shell and Spatial Structures", hosted by the International Association for Shell and Spatial Structures (IASS), and chaired by the guest editors of this issue. We thank the IASS for their support and invite all interested readers of this IJSS issue to join Working-Group 18 , as we will continue generating fascinating discussions on upcycling structures.

Waste - whose etymological root $* h_{1} w e h_{2}$ - means "to leave, abandon, give out" urgently be reclaimed by structural designers. Because of its ubiquity, diversity and historical marginalization, waste upcycling in structural applications is a source of yet untapped technological developments. By providing a ready-to-use, time-proven mechanical behavior, upcycled waste presents a one-of-a-kind industrial value. By exhibiting non-duplicable physical traces of its prior purpose or of wear and tear, upcycled waste can have more cultural or aesthetic value than any newly-manufactured materials. By avoiding the production of new materials, upcycled waste 
presents a unique potential to alleviate global warming and resource depletion. In short, waste may be of higher value for future human developments than any other construction material. It is the structural designers' and researchers' current duty to make this possibility a reality.

C. Fivet, O. Baverel

\section{References}

1. International Energy Agency, Material Efficiency in Clean Energy Transitions, Paris: International Energy Agency, 2019.

2. European Commission, Development and implementation of initiatives fostering investment and innovation in construction and demolition waste recycling infrastructure, Brussels: European Commission, 2018.

3. A. Steer, "Resource Depletion, Climate Change, and Economic Growth," in Towards a Better Global Economy: Policy Implications for Citizens Worldwide in the 21st Century, Oxford, Oxford University Press, 2014, pp. 381420.

4. United Nations, Department of Economic and Social Affairs, Population Division, "World Population Prospects: The 2017 Revision, Key Findings and Advance Tables.," 2017.

5. Wiktionary, "Reconstruction:Proto-Indo-European/h $\mathrm{h}_{1} \mathrm{weh}_{2}$,", 0711 2021. [Online]. Available: https://en.wiktionary.org/ wiki/Reconstruction:Proto-Indo-European/h\%E2\%82\%81 weh $\%$ E2\%82\%82-. 